\title{
Association Between Serum Sodium Abnormalities and Clinico- radiologic Parameters in Severe Traumatic Brain Injury
}

\author{
Philip Mwachaka ${ }^{1,2}$, Angela Amayo ${ }^{3}$, Nimrod Mwang'ombe ${ }^{1}$, Peter Kitunguu ${ }^{1}$ \\ ${ }^{1}$ Department of Surgery, Neurosurgery Unit, University of Nairobi, Nairobi, Kenya. \\ ${ }^{2}$ Department of Human Anatomy, University of Nairobi, Kenya. \\ ${ }^{3}$ Department of Pathology, University of Nairobi, Nairobi, Kenya.
}

Correspondence to: Dr. Philip Mwachaka; Email: pmaseghe@gmail.com

Received: 16 Jun 2020; Revised: 2 Feb 2021; Accepted: 19 Feb 2021; Available online: 3 Mar 2021

\begin{abstract}
Background: Secondary brain insults after traumatic brain injury such as electrolyte dysfunctions are associated with poor outcomes. This study aimed at determining the incidence of serum sodium ion abnormalities and their association with clinicoradiological parameters. Methods: A prospective crosssectional study of one hundred and seventeen patients with severe head injury. Data collected included patient demographics, prehospital interventions, clinical examination findings, computed tomography (CT) scan head findings, serum sodium ion levels (at admission and $48 \mathrm{~h}$ later), and outcome (30 days). Results: At admission, 93(79.5\%) patients had normal serum sodium ion levels. However, $48 \mathrm{~h}$ post-admission, hypernatremia was prevalent in 56(63.6\%) patients ( $\mathrm{p}<$ $0.001)$. Hypernatremia was significantly associated with the use of mannitol $(\mathrm{p}=0.036)$, lower Glasgow Coma Score $(p=0.047)$, higher Injury Severity Score $(p=$ $0.015)$, presence of subdural hematoma $(p=0.044)$, midline shift $>5 \mathrm{~mm}(\mathrm{p}=0.048)$, compressed/absent
\end{abstract}

basal cistern $(p=0.010)$, and higher Rotterdam CT Score $(p=0.003)$. Hypernatremia reported 48 h postadmission was associated with a high 30-day mortality rate [odds ratio (OR) 3.55, $\mathrm{p}=0.0095$ ]. Risk of mortality associated with hyponatremia and hypernatremia at admission was not statistically significant. Conclusion: While both hyponatremia and hypernatremia can occur in serious TBI patients, hypernatremia predominates 48 hours post-admission and is associated with statistically significant increased risk of death.

Keywords: Traumatic brain injury, hyponatremia, hypernatremia, outcomes, clinico-radiologic parameters

Ann Afr Surg. 2021; 18(3): 155-162

DOI: http://dx.doi.org/10.4314/aas.v18i3.6

Funding: None

(C) 2021 Author. This work is licensed under the Creative Commons Attribution 4.0 International License.

hyperosmolar therapies such as the use of hypertonic saline $(3,4)$. Hypernatremia is associated with increased mortality, longer hospitalization and greater hospital costs (3-5). Hyponatremia, serum sodium ion concentrations $<135 \mathrm{mmol} / \mathrm{L}$, may also occur after TBI and contributes to secondary brain insults by causing cerebral edema, seizures, and depression of consciousness (6). Hyponatremia in TBI is usually 
caused by cerebral salt wasting syndrome and syndrome of inappropriate secretion of antidiuretic hormone (7). Severe TBI, defined as Glasgow Coma Scale (GCS) $\leq 8$, is a major cause of death and incapacity worldwide and is associated with huge direct and indirect costs to the public (8-10). In addition, the World Health Organization projected that by 2020 , TBI would be the main cause of death and disability (11). TBI is more prevalent in developing nations because of the increasing number of road traffic accidents $(12,13)$. In our setup, most hospital-based studies have revealed that severe head injury is associated with mortality of $>50 \%$ and poor functional outcomes (14-16). These bad outcomes may be associated with secondary brain insults such as electrolyte abnormalities that arise from inflammatory and biochemical cascades initiated by the primary injury insult to the brain $(9,17,18)$. This study aimed at determining the incidence of serum sodium ion abnormalities in severe TBI patients, and their association with specific clinical and radiological parameters.

\section{Materials and methods \\ Study design and site}

An analytic cross-sectional study carried out over 4 months (1st November 2019 to 28th February 2020). The study site was the Kenyatta National Hospital Accident and Emergency Unit and Intensive Care Unit. Kenyatta National Hospital is located in Nairobi, Kenya and is the largest hospital and the main referral center for neurotrauma cases countrywide. The hospital serves patients from different regions and socioeconomic backgrounds.

\section{Study population}

All consecutive patients presenting with severe head injury defined by GCS $\leq 8$ and whose next of kin had given informed consent were recruited into the study. Patients with known pre-existing chronic illness were excluded from the study.

\section{Study variables}

Data collected included patient demographics, mechanisms of injury, prehospital interventions, clinical examination findings, computed tomography (CT) scan head findings, serum sodium levels (at admission and 48 h later), and outcome (30 days). The Injury Severity Score (ISS) was used to quantify the severity of injury to the patient (19). The serum sodium tests were done using Biolis 50i Superior Chemistry Analyzer (Boeki Medisys, Tokyo, Japan). Daily internal quality control checks were done to ensure that the results were valid. In addition, external quality control checks were done through the Randox International Quality Assessment Scheme (RIQAS). The reference range for serum sodium from our laboratory is $135-145 \mathrm{mmol} / \mathrm{L}$.

\section{Statistical analysis}

Data gathered was entered into Statistical Package for Social Sciences (SPSS) version 20.0 (IBM Corp; New York, United States of America) for analysis. Metric data are shown as means and standard deviation, nominal data as frequency and valid percent. Variables were tested for normal distribution using the Kolmogorov-Smirnov test in addition to histograms. If the assumption of normality was violated, MannWhitney U and Kruskal-Wallis tests were performed to test for differences between groups, instead of Student's t-test and analysis of variance (ANOVA) tests, respectively. Admission and 48-h post-admission variables were compared using the paired t-test. Categorical data was analyzed by Pearson's chi-square test. The correlation between the serum sodium and the study variables (clinical and radiological) was determined using Pearson's correlation coefficient (r). Odds ratios were calculated for each electrolyte abnormality to determine its associated risk of mortality (30-day mortality). A p-value of $<0.05$ was considered as significant.

\section{Ethical considerations}

We conducted this study in compliance with the principles of the Declaration of Helsinki. The study's protocol was reviewed and approved by the Kenyatta National Hospital - University of Nairobi Ethics and Research Committee (P723/08/2019). Written informed consent was obtained from the next of kin of the patients 
as the patients could not consent in view of their low GCS.

\section{Results}

\section{General information}

The study recruited 117 patients out of which 111 $(94.9 \%)$ were male. The mean age was $32.41 \pm 14.59$ years. Prehospital use of intravenous normal saline and mannitol solutions was reported in $65(55.6 \%)$ and 16 $(13.7 \%)$ of the patients, respectively. The mean GCS and ISS at admission were $6.41 \pm 1.69$ and $21.06 \pm 7.74$, respectively.

\section{Prevalence of serum sodium ion abnormalities}

The mean serum sodium ion levels at admission were $139.16 \pm 5.93 \mathrm{mmol} / \mathrm{L}(\mathrm{n}=117)$ and were $149.13 \pm 8.84$ $\mathrm{mmol} / \mathrm{L}(\mathrm{n}=88) 48 \mathrm{~h}$ after admission. Serum sodium ion abnormalities were seen in $24(20.5 \%)$ patients at admission and in $59(67 \%)$ patients $48 \mathrm{~h}$ post-admission. At admission, hyponatremia was the most common abnormality seen in $14(12.0 \%)$ patients while hypernatremia was noted in 10 (8.5\%) cases. Hypernatremia was the predominant abnormality in the 48 -h post-admission assay, reported in $56(63.6 \%)$ cases (Figure 1). Paired sample t-tests revealed a statistically significant difference between the admission and 48-h post-admission sodium levels ( $\mathrm{p}<0.001)$.

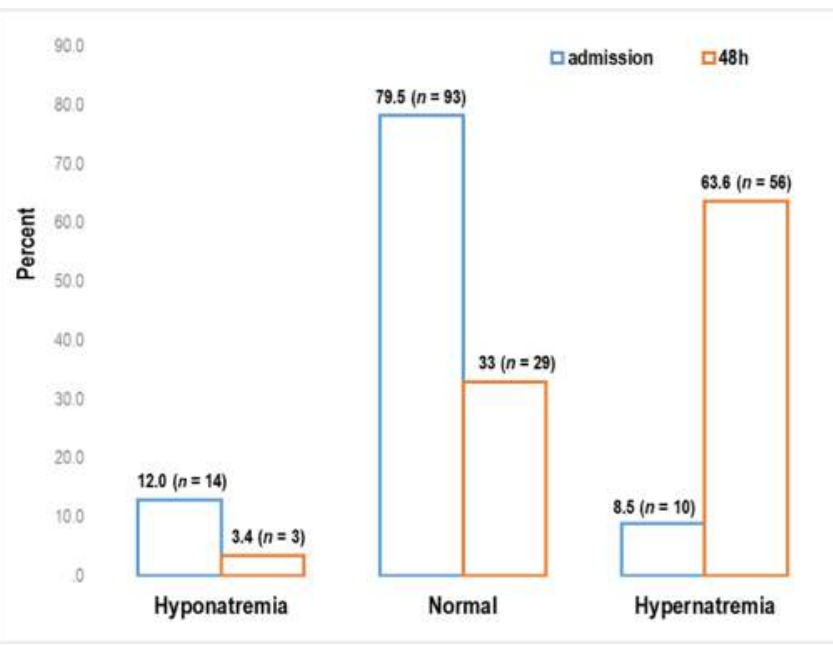

Figure 1. Serum sodium levels at admission and $48 \mathrm{~h}$ postadmission
Association between serum sodium and clinical parameters

Patients who presented with hyponatremia at admission took longer $(\mathrm{p}=0.002)$ to present to the hospital compared to the other groups (Table 1). Hypernatremia at admission was significantly associated with prehospital use of mannitol $(\mathrm{p}=0.036)$, while hypernatremia at $48 \mathrm{~h}$ post-admission was associated with a lower GCS $(p=0.047)$ and a higher ISS $(p=$ 0.015). Statistically significant negative correlations between admission sodium ion levels and duration of time from injury to hospital presentation ( $\mathrm{r}-0.226, \mathrm{p}$ $0.012)$, pre-hospital use of mannitol ( $\mathrm{r}-0.189, \mathrm{p} 0.036$ ), and GCS at admission ( $\mathrm{r}-0.205, \mathrm{p}$ 0.022) were noted (Table 2). The GCS ( $\mathrm{r}-0.225$, p 0.016), Abbreviated Injury Scale (AIS) for the head ( $\mathrm{r} 0.314, \mathrm{p} 0.003$ ), and ISS ( $r$ 0.236, p 0.027) were the only clinical variables that revealed statistically significant correlations with the 48-h post-admission sodium levels.

\section{Association between serum sodium and radiologic parameters}

Hypernatremia at admission was significantly associated with the presence of subdural hematoma $(\mathrm{SDH})(\mathrm{p}=0.044)$ and midline shift $(\mathrm{MLS})>5 \mathrm{~mm}(\mathrm{p}=$ 0.048 ), while compressed/absent basal cisterns ( $\mathrm{p}=$ $0.010)$, presence of SDH $(\mathrm{p}=0.032)$, and a higher Rotterdam CT Score $(p=0.003)$ were associated with hypernatremia developing $48 \mathrm{~h}$ post-admission (Table 3). These parameters also exhibited statistically significant positive correlations with the level of serum sodium ions (Table 4).

\section{Association between serum sodium and 30-day outcome}

The risk of death was higher in patients with hypernatremia compared to those with hyponatremia. Hypernatremia at admission and $48 \mathrm{~h}$ post-admission was associated with a higher 30-day mortality odds ratio (OR) 5.74 [95\% confidence interval (CI) 0.71-46.73, p 0.103 ] and OR 3.55 (95\% CI 1.36-9.23, p 0.0095), respectively. The risk of mortality associated with hyponatremia was OR 1.26 (95\% CI 0.41-3.93, p 0.688) 
MWACHAKA ET AL.

and OR 2.14 (95\% CI 0.17-26.33, p 0.552) at admission

and $48 \mathrm{~h}$ post-admission, respectively.

(63.6\%). Paired sample t-tests revealed statistically significant differences between the admission and $48 \mathrm{~h}$ post-admission sodium levels $(\mathrm{p}<0.001)$. Previous studies have also reported similar trends of initial

\section{Discussion}

In the current study, most (79.5\%) patients had normal serum sodium ion levels at admission. However, $48 \mathrm{~h}$ post-admission, hypernatremia was predominant normonatremia followed by hypernatremia in severe TBI $(5,20)$.

Table 1. Association between serum sodium and clinical parameters

\begin{tabular}{|c|c|c|c|c|c|}
\hline & & Hyponatremia & Normal & Hypernatremia & $p$-value \\
\hline \multirow[t]{2}{*}{ Age (years) } & Admission & $32.4 \pm 13.8$ & $31.9 \pm 14.8$ & $36.5 \pm 14.6$ & 0.649 \\
\hline & $\begin{array}{l}48 \mathrm{~h} \text { post- } \\
\text { admission }\end{array}$ & $20.7 \pm 2.1$ & $33.6 \pm 15.7$ & $34.4 \pm 13.7$ & 0.273 \\
\hline \multirow{3}{*}{$\begin{array}{l}\text { Time from injury to } \\
\text { presentation (h) }\end{array}$} & Admission & $59.7 \pm 28.7$ & $17.1 \pm 26.1$ & $24.1 \pm 24.9$ & $0.002 *$ \\
\hline & $\begin{array}{l}48 \mathrm{~h} \text { post- } \\
\text { admission }\end{array}$ & $48.8 \pm 60.4$ & $27.4 \pm 41.0$ & $21.5 \pm 37.7$ & 0.451 \\
\hline & Admission & $42.9 \%$ & $57.0 \%$ & $60.0 \%$ & 0.942 \\
\hline \multirow[t]{3}{*}{ Pre-hospital use of IV fluids } & $\begin{array}{l}48 \text { h post- } \\
\text { admission }\end{array}$ & $33.3 \%$ & $65.5 \%$ & $57.1 \%$ & 0.495 \\
\hline & Admission & $7.1 \%$ & $11.8 \%$ & $40.0 \%$ & $0.036^{*}$ \\
\hline & $\begin{array}{l}48 \mathrm{~h} \text { post- } \\
\text { admission }\end{array}$ & $0 \%$ & $17.2 \%$ & $12.5 \%$ & 0.652 \\
\hline \multirow[t]{2}{*}{ Systolic BP (mmHg) } & Admission & $126.4 \pm 22.7$ & $127.1 \pm 25.7$ & $131.2 \pm 26.1$ & 0.868 \\
\hline & $\begin{array}{l}48 \text { h post- } \\
\text { admission }\end{array}$ & $121.3 \pm 4.5$ & $134.6 \pm 22.2$ & $127.8 \pm 24.2$ & 0.364 \\
\hline \multirow[t]{2}{*}{ Diastolic BP (mmHg) } & Admission & $74.0 \pm 19.2$ & $76.5 \pm 18.0$ & $73.1 \pm 16.2$ & 0.754 \\
\hline & $\begin{array}{l}48 \mathrm{~h} \text { post- } \\
\text { admission }\end{array}$ & $61.3 \pm 10.0$ & $80.5 \pm 18.4$ & $73.9 \pm 14.7$ & 0.060 \\
\hline \multirow[t]{2}{*}{ Heart rate $(/ \mathrm{min})$} & Admission & $83.7 \pm 26.8$ & $95.8 \pm 25.0$ & $99.2 \pm 27.6$ & 0.233 \\
\hline & $\begin{array}{l}48 \mathrm{~h} \text { post- } \\
\text { admission }\end{array}$ & $69.3 \pm 5.1$ & $89.7 \pm 23.1$ & $95.0 \pm 26.6$ & 0.186 \\
\hline \multirow[t]{2}{*}{ Respiratory rate (/min) } & Admission & $19.8 \pm 5.9$ & $20.9 \pm 4.5$ & $21.7 \pm 4.1$ & 0.578 \\
\hline & $\begin{array}{l}48 \mathrm{~h} \text { post- } \\
\text { admission }\end{array}$ & $18.0 \pm 0.0$ & $20.4 \pm 3.6$ & $20.4 \pm 3.9$ & 0.567 \\
\hline \multirow[t]{2}{*}{ Saturation $\mathrm{O}_{2}(\%)$} & Admission & $94.6 \pm 5.5$ & $90.8 \pm 9.9$ & $89.8 \pm 10.4$ & 0.420 \\
\hline & $\begin{array}{l}48 \mathrm{~h} \text { post- } \\
\text { admission }\end{array}$ & $93.5 \pm 0.7$ & $93.2 \pm 7.7$ & $91.8 \pm 7.6$ & 0.746 \\
\hline \multirow[t]{2}{*}{ Total GCS } & Admission & $7.3 \pm 1.1$ & $6.3 \pm 1.7$ & $5.8 \pm 1.7$ & 0.064 \\
\hline & $\begin{array}{l}48 \mathrm{~h} \text { post- } \\
\text { admission }\end{array}$ & $7.7 \pm 0.6$ & $6.9 \pm 1.2$ & $6.2 \pm 1.3$ & $0.047 *$ \\
\hline \multirow[t]{2}{*}{ ISS } & Admission & $18.5 \pm 5.1$ & $21.6 \pm 8.3$ & $20.5 \pm 5.0$ & 0.333 \\
\hline & $\begin{array}{l}48 \mathrm{~h} \text { post- } \\
\text { admission }\end{array}$ & $18.7 \pm 1.2$ & $18.7 \pm 8.1$ & $22.1 \pm 7.6$ & $0.015^{*}$ \\
\hline
\end{tabular}


Serum Sodium Abnormalities And Clinico-Radiologic Parameters In SeVere Tbi

Table 2. Correlations between serum sodium and clinical parameters

\begin{tabular}{lcccc}
\hline \multirow{2}{*}{ Variable } & \multicolumn{2}{c}{ Admission $(n=117)$} & \multicolumn{2}{c}{$48 \mathrm{~h}$ after admission $(n=88)$} \\
\cline { 2 - 5 } & $\begin{array}{l}\text { Pearson's } \\
\text { correlation }\end{array}$ & $p$-value & $\begin{array}{l}\text { Pearson's } \\
\text { correlation }\end{array}$ & $p$-value \\
\hline Age (years) & 0.054 & 0.574 & 0.123 & 0.278 \\
Time from injury to presentation (h) & -0.226 & $0.012^{*}$ & -0.123 & 0.256 \\
Pre-hospital use of IV fluids & -0.024 & 0.788 & 0.013 & 0.902 \\
Pre-hospital use of mannitol & $-0.189^{*}$ & 0.036 & 0.014 & 0.900 \\
Mechanism of injury & -0.053 & 0.558 & 0.075 & 0.486 \\
Systolic BP & 0.040 & 0.659 & -0.078 & 0.471 \\
Diastolic BP & 0.000 & 0.996 & -0.069 & 0.522 \\
Heart rate & 0.143 & 0.123 & 0.178 & 0.103 \\
Respiratory rate & 0.103 & 0.298 & 0.068 & 0.558 \\
Temperature & -0.003 & 0.976 & -0.205 & 0.082 \\
Saturation $\mathrm{O}_{2}$ & -0.122 & 0.235 & -0.090 & 0.454 \\
Pupil examination & -0.046 & 0.611 & 0.195 & 0.068 \\
Total GCS & -0.205 & $0.022^{*}$ & -0.255 & $0.016^{*}$ \\
AIS - head & 0.083 & 0.359 & 0.314 & $0.003^{*}$ \\
ISS & 0.086 & 0.343 & 0.236 & $0.027^{*}$ \\
\hline AIS, abbris
\end{tabular}

AIS, abbreviated Injury Score; BP, blood pressure; ISS, Injury Severity Score; IV, intravenous. * $p$ value $<0.05$

Table 3. Association between serum sodium and radiologic parameters

\begin{tabular}{llllll}
\hline & & Hyponatremia & Normal & Hypernatremia & $P$-value \\
\hline SDH thickness (mm) & Admission & $10.0 \pm 5.0$ & $11.8 \pm 4.8$ & $9.2 \pm 2.0$ & 0.387 \\
& 48 h post-admission & $5.0 \pm 3.1$ & $12.5 \pm 2.7$ & $11.2 \pm 5.0$ & 0.343 \\
& Admission & $18.8 \%$ & $36.1 \%$ & $63.6 \%$ & $0.048^{*}$ \\
MLS $>5 \mathrm{~mm}$ & $48 \mathrm{~h}$ post-admission & - & $41.4 \%$ & $46.4 \%$ & 0.278 \\
Compressed or absent & Admission & $85.8 \%$ & $85 \%$ & $99 \%$ & 0.555 \\
basal cisterns & $48 \mathrm{hrs}$ post admission & $66.6 \%$ & $82.8 \%$ & $94.6 \%$ & $0.010^{*}$ \\
Presence of epidural & Admission & $7.1 \%$ & $23.7 \%$ & $10.0 \%$ & 0.250 \\
hematoma & 48 h post-admission & $.0 \%$ & $31.0 \%$ & $17.9 \%$ & 0.245 \\
& Admission & $42.9 \%$ & $31.2 \%$ & $70.0 \%$ & $0.044^{*}$ \\
Presence of SDH & $48 \mathrm{~h}$ post-admission & $33.3 \%$ & $20.7 \%$ & $50.0 \%$ & $0.032^{*}$ \\
Presence of traumatic & Admission & $21.4 \%$ & $37.6 \%$ & $50.0 \%$ & 0.333 \\
SAH & $48 \mathrm{~h}$ post-admission & $33.3 \%$ & $31.0 \%$ & $46.4 \%$ & 0.378 \\
Presence of contusion & Admission & $42.9 \%$ & $44.1 \%$ & $40.0 \%$ & 0.968 \\
hemorrhages & $48 \mathrm{~h}$ post-admission & $33.3 \%$ & $31.0 \%$ & $48.2 \%$ & 0.300 \\
Rotterdam CT Score & Admission & $3.6 \pm 1.0$ & $3.8 \pm 1.2$ & $4.4 \pm 1.0$ & 0.227 \\
& $48 \mathrm{~h}$ post-admission & $3.3 \pm 1.5$ & $3.4 \pm 1.0$ & $4.2 \pm 1.1$ & $0.003^{*}$ \\
\hline
\end{tabular}

CT, computed tomography; MLS, midline shift; SAH, subarachnoid hemorrhage; SDH, subdural hematoma. * $p$ value $<0.05$ 
MWACHAKA ET AL.

Table 4. Correlations between serum sodium and radiologic parameters

\begin{tabular}{llcc}
\hline & Test & Admission $(n=117)$ & $48 \mathrm{~h}$ after admission $(n=$ \\
& Pearson's correlation & 0.134 & 0.340 \\
Rotterdam CT Head Score & Sig. (two-tailed) & 0.151 & $0.001^{*}$ \\
MLS (mm) & Pearson's correlation & 0.210 & 0.129 \\
& Sig. (two-tailed) & $0.019^{*}$ & 0.232 \\
Basal cisterns & Pearson's correlation & 0.001 & 0.340 \\
& Sig. (two-tailed) & 0.994 & $0.001^{*}$ \\
Presence of epidural Hematoma & Pearson's correlation & -0.038 & 0.072 \\
Presence of SDH & Sig. (two-tailed) & 0.681 & 0.506 \\
& Pearson's correlation & 0.096 & 0.248 \\
Presence of intracerebral & Sig. (two-tailed) & 0.303 & $0.020^{*}$ \\
hematoma & Pearson's correlation & 0.025 & -0.144 \\
Presence of traumatic SAH & Sig. (two-tailed) & 0.789 & 0.181 \\
\multirow{2}{*}{ Presence of contusion } & Pearson's correlation & 0.136 & 0.138 \\
hemorrhages & Sig. (two-tailed) & 0.143 & 0.199 \\
Epidural hematoma volume (ml) & Pearson's correlation & 0.010 & -0.154 \\
& Sig. (two-tailed) & 0.917 & 0.151 \\
SDH thickness (mm) & Pearson's correlation & 0.250 & -0.022 \\
& Sig. (two-tailed) & 0.389 & 0.949 \\
Intracerebral hematoma volume & Pearson's correlation & -0.070 & 0.073 \\
(ml) & Sig. (two-tailed) & 0.690 & 0.703 \\
& Pearson's correlation & 0.064 & 0.357 \\
& Sig. (two-tailed) & 0.880 & 0.432
\end{tabular}

CT, computed tomography; MLS, midline shift; SAH, subarachnoid hemorrhage; SDH, subdural hematoma. * $p$ value $<0.05$

A retrospective study of 588 severe TBI patients by Vedantam et al. (5) reported a $79.3 \%$ incidence of hypernatremia diagnosed within the first week of admission, with the highest numbers being reported within $72 \mathrm{~h}$. Another retrospective study of 130 severe TBI patients reported $2.3 \%$ with hypernatremia at admission, but the cases of hypernatremia increased to $51.5 \%$ in the course of intensive care unit (ICU) stay (20). Rafiq et al. also reported hypernatremia in $65.1 \%$ of all patients with severe TBI (2).

Severe TBI patients have a high risk of developing hypernatremia over the course of their ICU stay, due to the coexistence of predisposing conditions such as impaired sensorium, altered thirst, central diabetes insipidus with polyuria, increased insensible losses, and use of hyperosmolar therapies such as mannitol and hypertonic saline $(3,4,21)$. Although it is possible that these mechanisms contributed to the occurrence of the delayed hypernatremia reported in the current study, either in isolation or combination, it is more likely that the sequelae of primary brain injury contributed more to this finding. In support of this, admission GCS, ISS, Rotterdam CT Head Score, degree of compression of the basal cisterns, and the presence of SDH were significantly correlated $(\mathrm{p}<0.001)$ with the levels of serum sodium ions $48 \mathrm{~h}$ after admission.

Few studies have described the association between sodium abnormalities and clinic-radiologic parameters. Li et al., also reported an association between admission GCS and the severity of hypernatremia (22). These authors reported that the severe hypernatremia group had a significantly lower GCS compared to moderate, mild hypernatremia, and normal sodium groups (median GCS, 3.0 vs. 5.0, 6.0, and 8.0, respectively). In the current study, the clinical parameters that have significant correlations with sodium ion levels, 
especially $48 \mathrm{~h}$ post-admission, were the GCS, AIS (head), and the sum ISS. In 2111, A study by Paiva et al. revealed that the presence of subdural and intracerebral hematomas was associated with the occurrence of sodium disorders in severe TBI patients (23). In the present study, the only mass lesion that was significantly associated with sodium abnormalities was the presence of an SDH. Besides, the Rotterdam CT Head Score and the state of the basal cisterns displayed statistically significant positive correlations with the sodium ion levels.

In the current study, hypernatremia was associated with a high rate of mortality of $73.3 \%$. Hypernatremia among TBI patients has been reported as an independent risk factor for mortality in previous studies $(5,20-22)$. According to Maggiore et al., hypernatremia in severe TBI patients is associated with a three-fold increase in the risk of ICU death (20). Li et al. reported mortality rates for the mild, moderate, and severe hypernatremia groups as $20.6 \%, 42.4 \%$, and $86.8 \%$, respectively, while that for the normonatremia group was $2.0 \%$ (22). Vedantam et al. also reported that hypernatremia was a significant predictor of mortality in TBI patients and that the mortality rates increased with the severity of hypernatremia (hazard ratios for mild, moderate, and severe hypernatremia were 3.2, 5.1, and 7.9, respectively) (5).

\section{Conclusion}

While both hyponatremia and hypernatremia can occur in severe TBI patients, hypernatremia predominates 48 $\mathrm{h}$ post-admission and is associated with statistically significant increased risk of mortality.

\section{Author Contributions}

Philip Mwachaka: conceptualization, data curation, methodology, formal analysis, investigation, writing original draft; Angela Amayo: conceptualization, methodology, resources, supervision, validation, writing - review and editing; Nimrod Mwang'ombe: conceptualization, methodology, resources, supervision, validation, writing - review and editing; Peter Kitunguu: conceptualization, methodology, resources, supervision, validation, writing - review and editing.
Conflicts of Interest: While one of the authors is a member of the editorial team, they were blinded during the review of the paper and were excluded from meetings where the manuscript was discussed

\section{References}

1. Pin-On P, Saringkarinkul A, Punjasawadwong Y, et al. Serum electrolyte imbalance and prognostic factors of postoperative death in adult traumatic brain injury patients: A prospective cohort study. Medicine (Baltimore). 2018; 97(45): e13081.

2. Rafiq MFA, Ahmed N, Khan AA. Serum electrolyte derangements in patients with traumatic brain injury. J Ayub Med Coll Abbottabad JAMC. 2013 ;25(1-2): 162164.

3. Hoffman H, Jalal MS, Chin LS. Effect of Hypernatremia on outcomes after severe traumatic brain injury: A nationwide inpatient sample analysis. World Neurosurg. 2018; 118: e880-e886.

4. Tan SKR, Kolmodin L, Sekhon MS, et al. The effect of continuous hypertonic saline infusion and hypernatremia on mortality in patients with severe traumatic brain injury: a retrospective cohort study. Can J Anaesth J Can Anesth. 2016; 63(6): 664-673.

5. Vedantam A, Robertson CS, Gopinath SP. Morbidity and mortality associated with hypernatremia in patients with severe traumatic brain injury. Neurosurg Focus. 2017; 43(5): E2.

6. Kirkman MA, Albert AF, Ibrahim A, et al. Hyponatremia and brain injury: historical and contemporary perspectives. Neurocrit Care. 2013; 18(3): 406-416.

7. Sepehri P, Abbasi Z, Mohammadi NS, et al. Hyponatremia in traumatic brain injury patients: Syndrome of inappropriate antidiuretic hormone (SIADH) versus cerebral salt wasting syndrome (CSWS). J Inj Violence Res. 2012; 4(3 Suppl 1): 17.

8. Dang B, Chen W, He W, et al. Rehabilitation treatment and progress of traumatic brain injury dysfunction. Neural Plast. 2017; 2017(2017): 1582182.

9. Farrell D, Bendo AA. Perioperative management of severe traumatic brain injury: What is new? Curr Anesthesiol Rep. 2018; 8(3): 279-289.

10. Vella MA, Crandall M, Patel MB. Acute management of traumatic brain injury. Surg Clin North Am. 2017; 97(5): 1015-1030.

11. Hyder AA, Wunderlich CA, Puvanachandra P, et al. The impact of traumatic brain injuries: A global perspective. NeuroRehabilitation. 2007; 22(5): 341-353.

12. Kinyanjui B. Traumatic brain injury in Kenya: A preliminary review of the literature. SAGE Open. 2016; 6(1): 2158244016638392. 
13. Wong JC, Linn KA, Shinohara RT, et al. Traumatic brain injury in Africa in 2050: a modeling study. Eur J Neurol. 2016; 23(2): 382-386.

14. Kiboi JG, Kitunguu PK, Angwenyi P, et al. Predictors of functional recovery in African patients with traumatic intracranial hematomas. World Neurosurg. 2011; 75(5): 586-591.

15. Mwang'ombe NJM, Kiboi J. Factors influencing the outcome of severe head injury at Kenyatta National Hospital. East Afr Med J. 2001; 78(5): 238-241.

16. Opondo EA, Mwangombe NJM. Outcome of severe traumatic brain injury at a critical care unit: a review of 87 patients. Ann Afr Surg. 2007; 1(1): 3-9.

17. Galgano M, Toshkezi G, Qiu X, et al. Traumatic brain injury: Current treatment strategies and future endeavors. Cell Transplant. 2017; 26(7): 1118-1130.

18. Prins $M$, Greco $T$, Alexander $D$, et al. The pathophysiology of traumatic brain injury at a glance. Dis Model Mech. 2013; 6(6): 1307-1135.

19. Copes W, Champion H, Sacco W, et al. The Injury Severity Score revisited. J Trauma Inj Infect Crit Care. 1988; 28(1): 69-77.

20. Maggiore U, Picetti E, Antonucci E, et al. The relation between the incidence of hypernatremia and mortality in patients with severe traumatic brain injury. Crit Care. 2009; 13(4): R110.

21. Kolmodin L, Sekhon MS, Henderson WR, et al. Hypernatremia in patients with severe traumatic brain injury: a systematic review. Ann Intensive Care. 2013;3: 35 .

22. Li M, Hu YH, Chen G. Hypernatremia severity and the risk of death after traumatic brain injury. Injury. 2013; 44(9): 1213-1218.

23. Paiva WS, Bezerra DAF, Amorim RLO, et al. Serum sodium disorders in patients with traumatic brain injury. Ther Clin Risk Manag. 2011; 7: 345-9. 